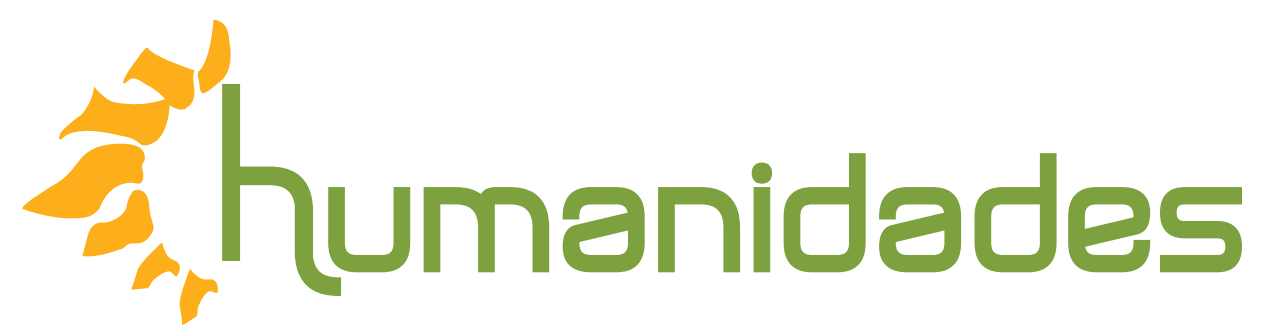

Revista humanidades

Enero-Junio, 2015 • Volumen 5, Número 1 • ISSN 2215-3934・pp. 1-30

\title{
Marcos narrativos y emergentes contra-narrativos de la violencia en Colombia
}

DOI: http://dx.doi.org/10.15517/h.v5i1.19384

Recibido: 20-Enero-2015 / Aceptado: 13-Abril-2015

\section{Catalina Cartagena Núñez.}

Magister en Ciencias Sociales de la Universidad General Sarmiento, Argentina y Socióloga de la Universidad Nacional de Colombia. Consultora independiente.

Correo electrónico: catacartagena.un@gmail.com 


\section{Marcos narrativos y emergentes contra-narrativos de la violencia en Colombia}

\section{Resumen}

En un primer momento, en este artículo se pretende mostrar cómo la violentología, en tanto saber experto sobre la violencia en Colombia, desplegó una macrolectura de país que facilitó la representación de la violencia en términos temporales, esto es, pasado, presente y futuro; y al mismo tiempo concentró sentidos sociales e institucionales, movilizando y reconfigurando un régimen de verdad sobre esta. Luego, en un segundo momento, se procura abordar las contra-narrativas emergentes; se exponen la lucha de sentido y las lecturas alternativas en torno al fenómeno.

\section{Marcos emerging narrative and counter- narrative of violence in Colombia}

\footnotetext{
Abstract

In this article, I intend to show, in the first place, how violentology as expert knowledge about violence in Colombia deployed a macroreading of the country which facilitated the representation of violence in terms of time, i.e., past, present and future, and at the same time concentrated social and institutional senses mobilizing and reconfiguring a system of truth about it. Then, in second place, I try to address the emerging counter-narratives exposing the struggle for meaning and alternative readings on the phenomenon.
}

Palabras clave:

Violencia, violentología, régimen de verdad, narrativas, contranarrativas.
Keywords:

Violence, violentology, regime of truth, narratives, counter-narratives. 
Marcos narrativos y emergentes contra-narrativos ...

Durante los años ochenta en Colombia, se gestó una creciente demanda gubernamental de estudios calificados sobre la violencia. Este fenómeno que azotaba fuertemente al país, a grupos de versados intelectuales, a humanistas y a científicos sociales; renovó de alguna manera las relaciones entre intelectuales y Estado. El punto cumbre lo alcanzó la famosa convocatoria de la "Comisión de Estudios sobre la Violencia”, solicitada por el gobierno de Virgilio Barco (19861990), y la publicación del informe Colombia: Violencia y Democracia en 1987. La comisión se organizó de la mano de condiciones sociales y políticas específicas de la época, estas contribuyeron a la consagración de un saber experto particular, denominado en su momento como "violentología"1.

Así las cosas, bajo el manto de este saber se convocó a un conjunto de expertos académicos designados "violentólogos" (concentrados en el IEPRI -Instituto de Estudios Políticos y Relaciones Internacionales-) quienes autorizados y avalados por los distintos gobiernos, elaboraron informes a través de los cuales conceptualizaron, definieron, diagnosticaron, recomendaron e intervinieron sobre la violencia. En esta medida, los intelectuales académicos asumieron, en este ciclo político, la función de especialistas en la interpretación del fenómeno y se convirtieron en artífices de la definición de una nueva política sobre el orden público y la paz.

Dicho lo anterior, por una parte, en este texto se muestra cómo la violentología, en tanto saber experto sobre la violencia, desplegó una macro-lectura de país que facilitó la representación de la violencia en términos temporales, esto es, pasado, presente y futuro; y al mismo tiempo, concentró sentidos sociales e institucionales alrededor de esta, movilizando y reconfigurando un régimen de verdad sobre la violencia. Para cumplir este objetivo, se analizará la interpretación propuesta en el informe Colombia: Violencia y Democracia, en tanto dispositivo de sentido que constituyó el saber experto "violentológico". Por otro lado, se abordarán las contranarrativas emergentes en el campo, se expondrán la lucha de sentido y las lecturas alternativas en torno al fenómeno. 
Huelga aclarar que aunque este artículo se concentra en el contexto social colombiano, procura brindar herramientas para colaborar en la comprensión de las relaciones entre las formas del poder y la producción de sentido sobre los fenómenos sociales; estas herramientas resultan útiles si se parte de que dichas relaciones son extensibles al ámbito general latinoamericano.

La "Comisión de Estudios sobre la Violencia” de 1986, a través de su informe y sus expertos, movilizó narrativas y construyó "marcos generales de sentido" (Allier, 2010, p. 17), esto es, de representación pública sobre lo ocurrido en los marcos de temporalidad: pasado, presente y futuro. Así las cosas, se definió la coyuntura crítica de la violencia de los años cincuenta, aludiendo a un pasado de violencia política; se delimitó lo acontecido en la década de los ochenta, diagnosticando un presente de múltiples violencias; y se construyó una expectativa de futuro basada en la resolución de conflictos, el pacto nacional y la neutralización de la violencia.

Los "referentes narrativos" o "tramas narrativas" (Jaramillo, 2011a), derivados de la Comisión, brindaron explicaciones suficientemente comprensibles e inteligibles sobre la realidad social. Además, aglomeraron una diversidad de interpretaciones sobre la violencia con efectos de verdad particulares. ${ }^{2} \mathrm{Al}$ mismo tiempo, estos referentes estuvieron determinados por las circunstancias políticas del momento y por los intereses en juego de los actores involucrados, esto es, la demanda social de una apertura democrática, la necesidad de legitimar el proyecto de paz mediante la gestión intelectual y la voluntad nacional de construir un nuevo pacto social.

El proceso narrativo sobre la violencia en Colombia contiene una particularidad contextual que la diferencia de otros procesos nacionales que también han sufrido lógicas violentas. Esta particularidad radica en la superposición de los "tempos" del conflicto, es decir, en la trasposición del pasado de "La violencia" de mitad de siglo XX, con el pasado de "las violencias" desarrolladas a partir de los años ochenta. De ahí, que en Colombia se haga referencia a estos pasados como "pasados recientes",

\section{Producción de referentes narrativos temporales sobre la violencia}

\section{La narrativa de la violencia ¿Continuidad o discontinuidad histórica?} esto es, como: 
Un pasado abierto, de algún modo inconcluso, cuyos efectos en los procesos individuales y colectivos se extienden hasta nosotros y se nos vuelven presentes. De un pasado que irrumpe imponiendo preguntas, grietas, duelos. [...] Se trata en suma de un pasado "actual" o, más bien, de un pasado en permanente proceso de actualización y que, por lo tanto, interviene en las proyecciones a futuro elaboradas por sujetos y comunidades (Franco y Levín, 2007, p. 31).

Pero, adicionalmente, la superposición temporal envuelve no solo a los pasados inacabados, sino a los presentes dilatados que impiden establecer cortes analíticos u históricos; e incluye a los futuros inciertos que no encuentran, aún en el horizonte de posibilidades, un escenario nacional de finalización del conflicto. Desde esta perspectiva, pareciera que intentar delimitar cronológicamente los acontecimientos y fechas que enmarcan el pasado reciente de "La Violencia" y de "las violencias" carece de sentido, pues este pasado se encuentra inserto en un campo narrativo en constante movimiento, con periodizaciones variables y flexibles. De acuerdo con esto, el proceso narrativo sobre la violencia posee no solo particularidades metodológicas o epistemológicas, sino fundamentalmente políticas, pues su "objeto" narrable contiene cuestiones de fondo que interpelan a la sociedad contemporánea y que "transforma los hechos y procesos del pasado cercano en problemas del presente" (Franco y Levín, 2007, p. 35).

Bajo este marco de superposición temporal, no obstante, se pueden diferenciar dos vertientes narrativas generales que se han construido sobre la violencia y en las que han confluido, sin mucha diferencia, relatos vinculados a la violencia política y relatos vinculados a las múltiples formas de violencia delincuencial. Así las cosas, la primera vertiente le concede a la violencia un carácter continuo y presente en la historia nacional: estamos signados por una "guerra endémica, permanente" (Sánchez, 2007, p. 17). 
La segunda concibe la violencia desde una matriz interpretativa de discontinuidad, esto es, como "fenómenos discontinuos, que irrumpen por ciclos y temporadas en la vida nacional" (Jaramillo, 2011a, p. 29).

La primera perspectiva explica la violencia, en general, a partir de una especie de "origen" violento inherente al ser colombiano.3 Según esto, el "origen" de la violencia se extendería hasta las guerras civiles del siglo XIX, pasando por "La Violencia" de mitad de siglo XX vinculada al enfrentamiento entre los partidos tradicionales, las cuales contendrían las bases explicativas de las violencias de los años ochenta y estas, a su vez, las bases de las violencias contemporáneas. Así las cosas, desde esta perspectiva cada narrativa de la violencia tiene como trasfondo la confluencia de las violencias pasadas y las violencias presentes.

A contrapelo de lo anterior, la segunda matriz interpretativa apela a la lógica de discontinuidad. Así pues, a pesar de la existencia de una violencia prolongada en el tiempo, esta tiene la capacidad de transformar los contextos, los actores y las intenciones (Jaramillo, 2011a, p. 32). Por eso insisten, los que comulgan con esta visión, en que resulta erróneo leer la totalidad de la historia nacional desde una lente interpretativa sostenida sobre una lógica que prioriza una tendencia lineal de la violencia y desconoce las diferentes dinámicas contextuales. Apoyados en datos estadísticos -si bien se reconoce que estos datos no son explicativos del fenómeno, pero sí representan un importante indicador (Palacio, 1990, p. 177)-, pero sin dar cuenta de una definición concreta de lo que entienden por violencia, los investigadores que adhieren a esta perspectiva demuestran que las cifras respecto a la criminalidad fluctúan a lo largo de los años; por lo tanto, afirmar una continuidad histórica de la violencia parece ser un argumento débil (Palacios, 2002; Rubio, 1999; Gaitán Daza, 1989). 
A este punto, dos posturas marcan la pauta. Por un lado, la del historiador británico Malcom Deas quien opina que la matriz de continuidad es reflejo de un "vicio profesional en los historiadores; un sentimentalismo que consiste en buscar lo viejo en lo nuevo" (2007, p. 81). De ahí que considere imperativo vigorizar una línea de análisis histórico que señale las discontinuidades más que las continuidades entre las etapas de la violencia. Por otro lado, y con este mismo perfil, la postura de Daniel Pécaut quién insiste en que, a pesar de que en los relatos siempre haya continuidades, a nivel procesual las rupturas son evidentes, un ejemplo de esto fueron las delimitaciones regionales y características particulares locales de los conflictos agrarios desarrollados en la época de "La Violencia" (2003, p. 36).

En resumen, el panorama general de relatos que interpretan la violencia colombiana -desde las guerras civiles del Siglo XIX, la violencia bipartidista de los cincuenta y las violencias de los ochentas-, apelan a la defensa de la condición endémica que explica la violencia desde una lógica de causalidad; o bien a la custodia de la perspectiva de discontinuidad procesual. Aún con sus fundamentos epistemológicos diferenciados, ambas vertientes articulan un marco de inteligibilidad general que permite cierta comprensión sobre el fenómeno de la violencia en Colombia en sus tres dimensiones temporales: argumentan una explicación sobre el pasado violento, realizan un diagnóstico del presente y elaboran lecturas posibles sobre el futuro próximo.

Si bien las dos perspectivas narrativas, continuidad/discontinuidad, han estructurado los debates sociales sobre la violencia, la Comisión de Estudios de 1986 elaboró el informe Colombia: Violencia y Democracia, bajo la lógica de la primera vertiente. Así pues, la lectura de continuidad defendida por amplios sectores sociales, institucionales y mediáticos fue validada por los expertos de la "violentología".

\section{La macro- lectura temporal del informe "Colombia: Violencia y Democracia"}


En este marco, bajo el espectro de múltiples violencias que desbordan la violencia política, el informe desplegó tres ejes interpretativos que revelan, en buena medida, la clave de lectura: representación y narración del pasado, el presente y el futuro. Lo anterior, a partir de las matrices cultura de la violencia, cultura democrática y nuevo pacto social (Jaramillo, 2011a).

El primer eje interpretativo explica el pasado violento, a partir de la controversial hipótesis de la cultura de la violencia. En esta instancia, la violencia es presentada como "una espiral, que de generación en generación, ha venido ascendiendo" (CVD, 1987). Si bien la premisa de la cultura de la violencia aparece incesantemente en el texto, las condiciones que señalan las posibilidades de revertirla también son una constante. Afirmaciones como "el reto con vista al futuro, sea buscar los mecanismos para sustituir la cultura de la violencia por una cultura de la paz y la democracia" (CVD, 1995, p. 22) dan muestra de ello. Por lo tanto, el informe se refiere a la cultura de la violencia no como a algo inexorable o esencial que determina la vida nacional, tal y como lo suponen otras narrativas, sino como regularidades y tendencias explicativas que, de acuerdo con la matriz de continuidad, revelan un presente condicionado por las dinámicas de un pasado violento, pasado que, sin embargo, puede enmendar su camino con altas cuotas de democratización (Jaramillo, 2011a, p. 239).

Dicho lo anterior, la tesis que explica la cultura de la violencia también revela dos razones fundamentales por las cuales esta desborda la concepción de ineluctabilidad. Primero, porque no es una violencia sino muchas, diversas en forma y contenido. Segundo, porque a través de un canje de cultura de violencia por cultura democrática es posible romper la espiral violenta del presente, con posibilidades de neutralizarla definitivamente en el futuro. En este sentido, sostiene el informe "es indispensable profundizar la democracia como antídoto de la violencia” (CVD, 1995, p. 27). 
El segundo eje interpretativo del informe Colombia: Violencia y Democracia hace referencia a la noción apertura democrática. Bajo un diagnóstico de presente, basado en la idea de que las violencias múltiples si bien son analíticamente diferenciables en la realidad entran en complejos procesos combinatorios, se llega a la conclusión de que la solución transversal a todas estas es una extensión de civilidad e igualdad, pero sobre todo una extensión de democracia a todos los ámbitos de la vida colectiva (CVD, 1995, p. 30). Con esta resolución la comisión no solo realizó un diagnóstico de las violencias, sino que propuso el ejercicio de una cultura de paz basada en la apertura democrática como alternativa para desarticularlas. En este sentido, y parafraseando a Darío Restrepo (1990, p. 209), perfeccionar la democracia representativa y consultiva apareció como el camino para ampliar la participación de la sociedad en las instituciones, de la mano de las negociaciones, pactos y concertaciones entre los grupos de presión y de estos con las instituciones públicas.

Así las cosas, desde la idea de democracia plasmada en el informe y pensada desde los marcos teóricos y políticos generalizados de la época y de la región, se planteó la necesidad de que el Estado reconociera una "sociedad civil plural en lo étnico, social y político" frente a la cual debían "imponerse esfuerzos para garantizar la libertad pero también acciones decididas para corregir la desigualdad" (CVD, 1995, p. 27-30). En definitiva, en una sociedad dividida en grupos de interés, la democracia como antídoto a la violencia consistía en el reconocimiento institucional de todos los actores sociales para que los conflictos se resolvieran por las vías legales. Es decir, se trataba de crear el ideal de democracia liberal representativa, pluralista y de libre competencia en un terreno de igualdad (Restrepo, 1990, p. 209). Adicionalmente, dentro de la perspectiva del informe el fortalecimiento de un estado de derecho implicaba, a su vez, el fortalecimiento de la sociedad civil, la cual tenía tanta responsabilidad en la superación de la violencia y la ampliación de la democracia como el propio Estado. "De allí que sea imperioso acometer 
decididamente reformas encaminadas a fortalecer los mecanismos de la sociedad" (CVD, 1995, p. 27-30). A pesar del carácter difuso del discurso democrático y de su contenido abstracto, el optimismo por construir una cultura democrática, basada en la apertura en el presente, marcó la pauta de las novedosas narrativas sobre la violencia que se produjeron a partir del informe de los expertos "violentólogos".

Finalmente, el tercer y último eje interpretativo del informe refiere a un pacto democrático pluralista como estrategia a largo plazo, es decir, de futuro próximo: "La comisión convoca explícitamente al país a buscar un pacto democrático, que sirva de propulsor de las urgentes transformaciones democráticas que exigen las instituciones políticas" (CVD, 1995, p. 52). En este sentido, la comisión asume que la superación definitiva de la violencia es posible a través de una apertura democrática sostenible en el tiempo y posibilitadora de un pacto de carácter nacional. Esta apertura implica el tratamiento integral del conflicto armado, a partir de soluciones políticas y negociadas; y a la desarticulación de las múltiples violencias, a través del fortalecimiento de la democracia (Jaramillo, 2011a, p. 242). Este pacto nacional, que contienen un proyecto democratizador de largo plazo, emerge, además, con un fuerte carácter incluyente de todos los sectores sociales. Por lo tanto, bajo esta perspectiva, no solo resulta tarea del gobierno, sino del conjunto nacional, contribuir a la concreción de una alianza pluralista y democrática que rompa con los legados del pacto bipartidista y elitista del Frente Nacional. ${ }^{4}$ De esta forma, plantea el informe:

Empero, la superación de la violencia y la ampliación de la democracia no incumben solo al Gobierno, ni siquiera al Estado en su conjunto, sino a todo el pueblo, de manera especial a los gremios tanto de trabajadores como de empresarios, a los partidos políticos, a los medios de comunicación, a la propia guerrilla (CVD, 1995, p. 29). 
De acuerdo con el sociólogo colombiano Jefferson Jaramillo, este discurso tuvo costos políticos importantes, pues difuminó las responsabilidades específicas de la violencia bajo el manto de las narrativas democráticas. Así, en el pacto construido desde la sociedad civil y materializado en la Constitución Política de 1991 (donde se vieron recogidas gran parte de estas exigencias democratizadoras) las violencias terminaron siendo concebidas como "responsabilidad de todos" (Jaramillo, 2011a, p. 243).

En síntesis, el informe Colombia: Violencia y Democracia se convirtió rápidamente en una pauta interpretativa de "La Violencia" de mitad de siglo y de las violencias múltiples contemporáneas. La descripción y caracterización de las violencias y sus perspectivas democratizadoras derivaron en una novedosa lectura de la violencia en términos del pasado, el presente y el futuro. Como lo indica el historiador Gonzalo Sánchez, las ideas planteadas en el informe se interiorizaron rápidamente en el discurso social y político cotidiano; este se convirtió en un referente analítico en el ámbito académico e incluso fue tomado por distintas dependencias oficiales (1993, p. 43). A grandes rasgos, la oposición violencia-democracia, que configuró el hilo conductor del informe y tipificó las violencias en negociables y no negociables, se resolvió asumiendo un tratamiento general y democrático. En este marco, el criterio general de fortalecer a la sociedad civil como metodología para neutralizar la violencia, constituyó su columna vertebral.

La formulación de la nueva narrativa sobre la violencia integradora de la sociedad civil, anteriormente invisibilizada, respondió en buena medida a la pregunta "acerca de dónde había estado y qué había hecho, durante el período anterior, esa civilidad o esa ciudadanía que era convocada como sujeto privilegiado, garante y base identitaria de la democracia” (Rabotnikof, 2007, p. 17). Así pues, bajo el espectro de la "violentología", la sociedad civil, como nuevo actor interpelado y construido por el discurso democrático, fue decididamente incorporada. En definitiva, esta macro-lectura sobre la violencia de los años ochenta posicionó una interpretación 
particular sobre la época presente, pero también sobre el pasado y el futuro, estructurando así las representaciones sociales sobre la violencia.

En otras palabras, podemos decir que el informe Colombia: Violencia y Democracia trazó las coordenadas de orientación para comprender el conflicto y sentó las bases para la construcción de un lenguaje común que permitiera asimilar sus impactos y significados. Es decir, configuró y administró el sentido social de la violencia en tanto acontecimiento histórico, conformando así un "régimen de verdad" sobre la violencia.

Con el término "régimen de verdad" adoptado de la teoría del poder de Michel Foucault (1994), se hace referencia a aquellos discursos emblemáticos que se tornan hegemónicos en la escena pública al instaurar. Lo anterior, a través de prácticas y discursos diversos; de los marcos de selección de lo decible sobre la violencia; y de las claves interpretativas y estilos narrativos para evocarla, pensarla y transmitirla.

De acuerdo con esto, dentro de las propiedades distintivas de la "violentología", propuesta aquí como régimen de verdad, se pueden encontrar algunas generalidades: sus proposiciones organizaron el debate público, se convirtió en objeto privilegiado de las luchas por dotar de sentido la experiencia de la violencia, y moldeó y delimitó las interpretaciones divergentes.

No obstante, también se pueden encontrar algunas especificidades, por ejemplo, el informe Colombia: Violencia y Democracia constituyó una verdad cuya dimensión y alcances fueron novedosos, pues estuvo soportada por la fuerza academicistacientificista y consagrada por la condición oficial de la comisión que la produjo, en ese sentido, el prestigio de sus integrantes contribuyó a ampliar sus márgenes de legitimidad. Estas características particulares del contexto colombiano, que por entonces veía en la ciencia la búsqueda de la verdad, la razón y el desinterés; le concedieron credibilidad y aceptación general a su narrativa.

\section{La violentología como un "régimen de verdad"}


Otro ejemplo es que su perspectiva sobre la violencia integró los principios generales de la democracia política que se enraizaba con fuerza en la década de los ochenta, asimismo, tomó en cuenta los postulados de la política de paz del gobierno de Virgilio Barco. La articulación de estos factores resultó en un relato de época asociado a la paz negociada, a la seguridad ciudadana y a los nuevos pactos nacionales; coincidió, de esta forma, con el clima discursivo regional que encontró en la democracia el antídoto a la crisis de sentido de los años ochenta (Jaramillo, 2011a, p. 397).

La lectura analítica de la violentología (otra especificidad) estuvo determinada por la relación binaria entre cultura de violencia y cultura democrática. Lo anterior se convirtió, prontamente, en una clave interpretativa que articuló la estructura narrativa de los trabajos que le continuaron.

En definitiva, el informe de los violentólogos conformó un nuevo régimen de verdad al hacer inteligible un fenómeno que para la mayoría de colombianos no era comprensible, a través de una serie de enunciados, escritos y prácticas que lo calificaron. Con esta narrativa, académicos expertos y gobierno perfilaron una mirada sobre la violencia, realizaron un recorte explicativo e interpretativo sobre lo acontecido. Asimismo, instauraron y subvirtieron lecturas emblemáticas, legitimaron y alteraron interpretaciones históricas más generales de la realidad, memorias institucionales y sociales, experticias y saberes.

En síntesis, se puede advertir que la investigación de la comisión produjo efectos políticos importantes: surgió un conocimiento novedoso sobre la violencia en Colombia y se instauró un saber experto sobre esta. Además, su informe expuso una nueva verdad pública sobre "La Violencia" del pasado y las múltiples violencias del presente, conformando así una nueva clave interpretativa y narrativa para juzgar, pensar y evocar el pasado, el presente y el futuro. 
Ahora bien, el régimen de verdad violentológico tuvo serias consecuencias dentro del campo de estudios sobre la violencia en Colombia, pues gran parte de la historia y la narrativa nacional (que empezó a tematizar y circular sobre la violencia desde finales de los ochenta y principios de los noventa) fue abordada y elaborada desde el arquetipo presentado por el informe y las perspectivas de los expertos de la "Comisión de Estudios". Lo anterior ya sea compartiendo evidencias empíricas minúsculas, utilizando marcos teóricos comunes o bien distanciándose radicalmente de estos. En este sentido, de alguna u otra manera, los referentes narrativos construidos por la comisión impactaron y moldearon las narrativas de sus contemporáneos, así como de las nuevas generaciones, las cuales en comunión con las anteriores fueron completando "una gran trama global sobre la violencia" (Jaramillo, 2011, p. 247).

Sin embargo, si bien muchos se nutrieron de esta trama, otros más la confrontaron abiertamente. Desde el ámbito académico particularmente, las críticas pasaron por el plano de lo epistemológico y metodológico, por el ámbito de las temáticas gruesas, por las visiones tímidas que se asumieron en el diagnóstico y sobre los grandes pilares que soportaron la arquitectura conceptual del mismo: la cultura de la violencia y la cultura de la democracia (Jaramillo, 2011a, p. 254).

Entendemos las "contra-narrativas" como aquellas construcciones narrativas que desde marcos teóricos, metodológicos y posturas políticas diferenciadas, se propusieron críticamente señalar los vacíos argumentativos de la violentología y formular una explicación de la violencia alterna a la enunciada por los expertos.

\section{Contra-} narrativas sobre la violencia

A partir de lo anterior, y partiendo de dos corrientes teóricas particulares (la teoría crítica de la Escuela de Frankfurt y la tradición genealógica inaugurada por Nietzsche y continuada por Foucault), las contra-narrativas sobre la violencia se concentraron en señalar las insolvencias del discurso oficial sobre la violencia construida por la alianza expertos-gobierno. 
La crítica principal a la violentología se realizó en torno a la "definición legítima" de la violencia dentro de los cánones académicos, en tanto campo de acción donde se insertó la lógica de la comisión. La diatriba estuvo basada en la tesis de que los estudios sobre la violencia que tuvieron como punto de partida el informe de los comisionados, junto a los diversos entendimientos y conceptualizaciones de la misma, recogieron acríticamente el concepto de violencia. Esta impugnación tuvo lugar en un marco más amplio de objeciones que señaló que la violencia no solo se empezó a convertir en un terreno de saber sino también de poder: "No solo porque la violencia sea uno de los instrumentos del poder, sino porque lo que se dice sobre ella está entrecruzado por intereses estratégicos” (Palacio, 1990, p. 176). Así las cosas, según este punto de vista, el carácter acrítico de las conceptualizaciones sobre la violencia aportadas por los estudios dominantes sobre el tema, incluyendo especialmente el informe de la comisión de los violentólogos, tendió a ocultar un objetivo estratégico y concreto de relegitimación de un Estado de corte neoliberal (Palacio, 1990; Retrepo, 1990; Medellín, 1990).

El ocultamiento de dicho objetivo estratégico se evidenció a partir de tres elementos particulares. El primero tuvo que ver con la aceptación acrítica de la violencia ejercida conforme a derecho o legitimidad, esto es, de la violencia estatal propia de la corriente política liberal. El segundo, con la definición violentológica que apuntó a una neutralización de las luchas, al confundir en un mismo fenómeno los ataques contra los sectores populares y las luchas y resistencias contra el capital y otras clases dominantes. El tercer y último elemento tuvo que ver con el respaldo y aceptación de las formas de dominación renovadas, porque rechazando exclusivamente las formas de violencia asociadas a la fuerza física, la violentología guardó silencio respecto a las formas más sutiles.

Planteado el panorama general, a continuación se consideran a profundidad las tres vertientes problemáticas que, según las contra-narrativas, configuraron el carácter acrítico de la definición de la "violencia" en el discurso dominante violentológico 
y legitimaron el Estado capitalista a través de una definición estratégica para el poder. Dichas vertientes son: la comprensión liberal y sociológica del fenómeno de la violencia, el planteo de una multiplicidad de violencias indiferenciadas y el privilegio del análisis de la violencia física en tanto violencia visible.

A partir de la violentología se propusieron dos sistemas analíticos que, desde las causas estructurales e históricas o desde los actores y el régimen político, explicaron la violencia en Colombia. Ambas sistematizaciones, sin embargo, confluyeron en la adopción de los planteamientos liberales vinculados a la idea de la neutralidad del Estado y a las formas institucionales de la democracia. Para los autores de las contra-narrativas, particularmente, esta coincidencia derivó en una ausencia analítica sobre las relaciones entre el Estado, el régimen político y la acumulación del capital.

En este marco, desde la vertiente estructural se insiste que la causa de la violencia tiene que ver con el proceso incompleto de formación del Estado Nacional de la sociedad colombiana en tres ámbitos. Primero, el proceso inacabado de ocupación poblacional y económica del territorio. Segundo, la formación pre-moderna de los partidos tradicionales y la base de las instituciones republicanas que formalmente aparecen como modernas, pero que no corresponde con la realidad del país. Tercero, el proceso de creación de imaginarios políticos de diversos sectores sociales que logran integraciones culturales fragmentadas de los ciudadanos en sustitución de una identidad nacional debidamente materializada en el Estado. En síntesis, una ausencia de integración territorial, política y simbólica agravada por una incompleta integridad económica: una incompleta inserción al mercado mundial y la falta de consolidación de un mercado interno (Gonzales, 1989, p. 8).

Por su parte, desde la segunda vertiente, la violencia es explicada a partir de una crisis del régimen político generadora de violencia, acompañada de la 
emergencia de actores comprometidos en la ejecución de actos de violencia (Pizarro en Gonzales, 1989, p. 37). En este sentido, la situación de la crisis es presentada como "la incapacidad del régimen político de reformarse para contener las expresiones autónomas de protesta y de demanda de participación política, los mecanismos de criminalización de las manifestaciones sociales y las respuestas desinstitucionalizadas y violentas de los excluidos para abrir espacios de participación institucional” (Restrepo, 1990, p. 205).

No obstante, ambas vertientes, aún con sus diferencias analíticas y enfoques particulares, coincidieron en una explicación relacionada con la precariedad del Estado colombiano manifiesta en la no separación de los intereses públicos de la nación, de los intereses privados de sectores políticos y sociales; en la inexistencia de una igualdad jurídica entre los individuos; la ausencia de ciudadanía; y la

De la comprensión liberal y la comprensión sociológica carencia del monopolio de las armas en el Estado. Siguiendo el planteo del filósofo colombiano Darío Restrepo, en el fondo ambas posiciones advierten, por un lado, la naturaleza violenta de la sociedad, y por otro, el Estado como un logro de la civilización, es decir, como el instrumento neutral por excelencia para la pacífica resolución de los conflictos. En este sentido, continúa el autor, el Estado fuerte y reformado se funda por encima de los intereses privados, disciplinando la sociedad violenta bajo el imperio soberano de las instituciones públicas, del ejército y la ley impersonal (Restrepo, 1990, p. 207).

Así las cosas, el Estado sería ese cuerpo técnico burocrático "neutral" que está por encima de la sociedad, redentor de culpas y disciplinador de la original violencia social (Restrepo, 1990, p. 208). Al mismo tiempo, se reivindica la consolidación de un régimen político democrático como principal antídoto contra la violencia, esto es, la construcción de formas y prácticas institucionales de la democracia liberal. Desde esta perspectiva, apertura institucional, democratización del ejercicio del poder y pacto social para la paz, conforman el cuerpo general de reivindicaciones inmediatas que se erige contra la violencia. 
Bajo este tipo de explicaciones enraizadas a las formas jurídicas y estatales modernas de la teoría política de origen liberal, la definición de la violencia en Colombia se entendió como la utilización de la fuerza física o la amenaza que coarta la autonomía de la voluntad; pero también como un medio divorciado del derecho privado, diverso de la política como tal. Así, reza el informe: "Hay violencia en quién recurre a la fuerza, la coacción, el engaño y la muerte para apropiarse de bienes como en quien recurre a medios análogos para defenderlos" (CVD, 1987/1995, p. 23)

A partir de esa definición, emergen varias oposiciones. La primera es la oposición de la violencia frente a la autonomía de la voluntad, esto es, violencia versus libertad: lo violento es aquello que injustamente coarta nuestra voluntad. Esta oposición construyó una dicotomía que presentó a la violencia como un fenómeno anormal, es decir, extraño al orden social moderno. La segunda oposición que este discurso construyó tuvo que ver con el enfrentamiento entre una violencia legítima monopolizada por el Estado y otra ilegítima correspondiente a la ejercida por los ciudadanos o grupos sociales. ${ }^{5}$ Finalmente, la última oposición construida respondió a la separación sustancial entre la violencia y la paz. Del lado de la violencia reposaba un sinsentido, mientras del lado de la paz se ubicaron la política y el derecho.

Adicionalmente, una segunda definición sobre la violencia, exhortada por el informe y concebida desde una perspectiva sociológica, menciona que se trata de un proceso de desintegración social generado por diversos factores que lograron debilitar el orden político y social. De ahí el imperativo de construir nuevas formas de integración social que rompieran con la violencia, en tanto expresión trágica de la anomia (Palacio, 1990, p. 181). ${ }^{6}$ La violencia, entonces, se contrapuso al orden: "Por otro lado, conviene hacer resaltar que detrás de todas estas modalidades de violencia se encuentran causas que tienen que ver con el orden político y social. 
Por ejemplo, es notoria la fragilidad del Estado como espacio institucional en el cual se expresan la relación entre las fuerzas sociales, sus conflictos y finalmente la superación de estos" (CVD, 1987/1995, p. 22). Esta definición, heredera de lo postulado por Daniel Pécaut en su obra "Orden y violencia” (cuyo hilo argumentativo estaba en la oposición de estos dos términos), se traspuso a la distinción entre los social construido por el Estado (orden) y lo social que fluye por fuera del orden estatal (la violencia) (Sánchez Díaz, 2009, p. 45).

En esta explicación doble, liberal y sociológica, se encontraron insertas, a su vez, las fórmulas de solución a la violencia colombiana: un cierto fortalecimiento del Estado y de una democracia verdaderamente consensual. Desde esta perspectiva, resulta entendible la invocación al orden y la autoridad, la necesidad de reforzar el aparato estatal (o la apertura de los canales de expresión) y la participación política de los actores y sectores en conflicto, como las recomendaciones recurrentes de salida a la crisis (Medellín, 1990, p. 201).

Para los críticos del informe y de la definición "acrítica" de la violencia que este incluye, la comprensión liberal o sociológica de la violencia sirvió, a la larga, a un propósito consciente o inconsciente: la legitimación del Estado capitalista y la neutralización de las luchas populares (Palacio, 1990, p. 184).

¿Por qué a las diferentes formas de lucha o conflicto que se manifestaban en la coyuntura de los años ochenta se las designó por igual con el calificativo de "violencia"?, ¿qué intereses estratégicos sirvieron en la confusión de toda forma de lucha y resistencia de las clases y sectores subordinados con las formas de agresión y poder de las clases dominantes, el Estado y particularmente las fuerzas de seguridad, en torno a una denominación tal como "violencia"?

De las violencias
múltiples
equiparables y
la neutralización
de las luchas
populares


La formulación de estas preguntas por parte de los sectores críticos del informe respondió, en buena medida, a la explicación aportada por los comisionados que planteó una lógica de las múltiples violencias indiferenciadas y presentó el fenómeno como una lucha de todos contra todos, de tal manera que pareció enraizado a una cultura de la violencia de carácter irracional. La única diferencia manifiesta, entre las violencias desarrolladas, fue su carácter resolutivo entre negociables o no negociables. De esta forma, la violencia política, es decir, la violencia ejercida por la guerrilla y la violencia ejercida por el Estado, contaban con el mismo estatus, y estas, a su vez, tenían el mismo estatus que la violencia familiar, la ejercida por los medios de comunicación, la desplegada hacia las comunidades étnicas y la de las bandas criminales, entre otras. De ahí que para solucionar "las violencias", sin distinción, la democracia aparece como único antídoto transversal a todas ellas.

En este marco, la concepción de la violencia como "responsabilidad de todos" no solo consolidó una narrativa culpante que disipó las responsabilidades específicas de los actores, sino que equiparó las violencias con el objetivo explícito de condenar la violencia en cualquier manifestación. Esta experiencia puede cotejarse, aunque con debidas reservas, con el caso de Argentina en la década de los ochenta; con su narrativa democrática transicional como oferta de sentido, esto es, la "Teoría de los dos demonios", teoría que emparejó la violencia de Estado de la dictadura con la insurgencia ilegal de los grupos armados.

Para la filósofa argentina Nora Rabotnikof (2007) en términos del procesamiento judicial del pasado, la imputación a los dos demonios podía servir para evidenciar una justicia simétrica que sin distinciones condenara tanto a los miembros de las juntas militares como a los mandos de los grupos armados. Adicionalmente, esta fórmula "bidemoníaca" definió el lugar de la sociedad como víctima inocente, 
aterrorizada por dos fuerzas ajenas con las que no había tenido nada que ver, mitigando en ella cualquier forma colectiva de responsabilidad.

Así pues, mientras que en Argentina la "Teoría de los dos demonios", fuertemente debatida a partir de los noventas, afirmó la inocencia de la sociedad; el imaginario democrático colombiano, fundado en el informe Colombia: Violencia y

Democracia, ratificó su culpabilidad. No obstante, en ambos casos, inocentes o culpables, la imagen construida de la sociedad formó parte de una estrategia argumentativa inaugural que otorgó legitimidad a la llamada refundación republicana democrática. En el caso argentino, la república que emerge de las ruinas dejadas por la lucha entre los dos demonios. En el caso colombiano, la república que emerge de la ruptura con la cultura de la violencia enraizada en las profundidades del devenir histórico nacional. En los dos casos, la operación discursiva aspiró a colocar a los enemigos de la democracia en el pasado (los violentos de toda índole), para poder así nombrar a ese nuevo sujeto ciudadano (Rabotnikof, 2007, p. 19).

Finalmente, las contra-narrativas propusieron reformular la particularidad de las formas de violencia que los expertos de la "Comisión de Estudios" presentaron en sus análisis. Lo anterior porque consideraban que esta explicación, que entendía el conflicto o el desequilibrio como estados no deseables que debían ser eliminados, promovía la neutralización y estigmatización de cualquier reclamo y acción popular:

Con esa explicación es difícil distinguir entre aquellas luchas que apuntan a la defensa de los sectores populares, a fortalecer su organización o atacar el sistema político y social de aquellos que están orientados al reforzamiento de la dominación y explotación propias el sistema social que vivimos. También es difícil distinguir las acciones delincuenciales que apuntan al debilitamiento de las fuerzas populares, de aquellas que favorecen la acumulación por vías ilegales (Palacio, 1990, p. 188). 
En este sentido, la neutralización de las luchas implicaba también el planteamiento de una franca indiferencia frente al carácter innovador, creativo y vital de la lucha y resistencia de los diversos procesos y actores sociales (Palacio, 1990, p. 189). Este no reconocimiento contribuyó, en buena medida, a neutralizar su empuje y a dotar a las acciones de resistencia de un carácter de anormalidad.

El informe Colombia: Violencia y Democracia ejerció un rechazo simplista a la violencia vinculada con la fuerza física no legítima, es decir, a aquellas manifestaciones que desbordan la normatividad, sin cuestionar de fondo las formas de dominación consensuales y disciplinarias. Asimismo, refutó las formas de violencia institucional del Estado moderno capitalista.

Entonces, las contra-narrativas apelaron a buscar otras explicaciones sobre la violencia, a partir de tradiciones teóricas como la genealogía de Foucault, o bien, desde la perspectiva weberiana, que muestra que la dominación no concluye en la represión, sino que se hace presente también en los mecanismos administrativos o burocráticos.

Siguiendo al especialista en sociología jurídica, Germán Palacio, este señalamiento crítico revela facetas violentas que, a diferencia de la física, no son fácilmente visibles. En este caso, la violencia está asociada a un entendimiento más general, que abarcaría no solo fenómenos asociados a la fuerza física, sino otros más sutiles o con una presentación menos dramática y perceptible (Palacio, 1990, p. 183).

Justamente, esta argumentación pretende, desde un marco de la teoría crítica por un lado, y de la tradición filosófica de la genealogía por el otro, cuestionar la idea de la existencia del Estado capitalista como la expresión de un acuerdo de voluntades, es decir, como un acto no violento. Entonces, para rebatir esta concepción de "no violencia" de la fundación del Estado, esta crítica encabezada por Palacio muestra como la violencia no es solo aquella que vicia el contrato, sino que el contrato (la expresión misma de la libertad en el capitalismo) es en sí mismo un acto violento.

\section{Del privilegio de la violencia física como violencia visible}


Esto, por no ahondar en la crítica disparada por el movimiento feminista que señala la organización familiar y social de raíces patriarcales en sí misma violenta, la cual no necesariamente implica la utilización de las armas (Palacio, 1990, p. 184).

En definitiva, esta apertura conceptual es indicativa de lo insuficiente que resulta pensar las formas de la democracia y el régimen político solo desde el funcionamiento del sistema político nacional. De ahí que sea necesario indagar las relaciones entre la acumulación del capital, la configuración de las clases, las relaciones al interior de los sectores dominantes y de estos con el Estado, para de esta forma, abrir otras dimensiones analíticas al problema de la violencia. Así las cosas, de acuerdo con las perspectivas de las que aquí se denominan "contranarrativas", las causas de la violencia no se agotan en la precariedad del Estado o la debilidad de la sociedad y la antidemocracia del régimen político. La violencia es más que el "anormal" fluir de un país en construcción o la debilidad del caparazón democrático del sistema político. La violencia aparece como un instrumento estratégico para la extensión de la lógica del capital y de los sectores dominantes:

La violencia está instrumentalizando cambios bruscos en las relaciones de producción, está expulsando campesinos de sus tierras, destruyendo sindicatos para que nada se oponga a la acumulación, está abriendo nuevos frentes productivos y facilitando la inserción competitiva en el mercado mundial. La violencia refleja el ascenso de una burguesía emergente, la pugna entre sectores capitalistas por el control de la tierra, de las fuentes productivas y de los aparatos del Estado (Restrepo, 1990, p. 216).

En este artículo se demostró cómo el marco narrativo, materializado en el informe Colombia: Violencia y Democracia, desplegó una macro-lectura de país que facilitó la representación de la violencia en términos temporales: pasado, presente y futuro. Así pues, el informe definió la coyuntura crítica de la violencia de los 
años cincuenta aludiendo a un pasado de violencia política, delimitó lo acontecido en la década del ochenta diagnosticando un presente de múltiples violencias, y construyó una expectativa de futuro basada en la resolución de conflictos, el pacto nacional y la neutralización de la violencia. En este marco, bajo el panorama de múltiples violencias que exceden la violencia política, el informe desplegó tres ejes interpretativos que revelaron, en buena medida, la clave de lectura, representación y narración del pasado, el presente y el futuro, a partir de las matrices: cultura de la violencia, cultura democrática y nuevo pacto social (Jaramillo, 2011a).

Por lo anterior, se asume la tesis de que la macro-lectura de la violencia. presentada por los expertos a través del informe Colombia: Violencia y Democracia, movilizó y reconfiguró un "régimen de verdad" sobre la violencia en Colombia para las dos últimas décadas del siglo XX. Con el concepto "régimen de verdad", adoptado de la teoría del poder de Foucault (1994, 1994a), se argumenta que el informe Colombia: Violencia y Democracia instauró marcos de lo decible sobre la violencia, claves interpretativas y estilos narrativos para evocarla, pensarla y transmitirla.

En efecto, las proposiciones del informe organizaron el debate público, este se convirtió en objeto privilegiado de las luchas por dotar de sentido la experiencia de la violencia, asimismo, moldeó y delimitó las interpretaciones divergentes. A través de la narrativa, académicos expertos y gobierno afinaron una mirada sobre la violencia, realizaron un recorte explicativo e interpretativo sobre lo acontecido, instauraron y subvirtieron lecturas emblemáticas. También, legitimaron y alteraron interpretaciones históricas más generales de la realidad social. Sin embargo, en este escenario hegemónico de la violentología, emergieron contra-narrativas que confrontaron las visiones normativas establecidas por el régimen y realizaron lecturas alternativas sobre el fenómeno, a partir de marcos teóricos, metodológicos y posturas políticas diferenciadas. 
Marcos narrativos y emergentes contra-narrativos ...

Bajo la perspectiva de que la violentología recogió acríticamente el concepto de violencia y de que este campo de estudios no solo respondió a un campo de saber, sino inmediatamente a uno de poder, las contra-narrativas asumieron este saber experto como un saber instrumental para la relegitimación del Estado neoliberal (Palacio, 1990; Restrepo, 1990; Medellín, 1990). Puede concluirse, entonces, que el campo narrativo general sobre la violencia se constituyó como un espacio de lucha simbólica y política por dotar de sentido al fenómeno. 
1. El término "violentología" es aportado por una periodista de la revista política colombiana Semana en el contexto específico del "boom" de los estudios sobre la violencia. En general, hace referencia a la práctica de intelectuales de las ciencias sociales que se dedican exclusivamente al estudio de la violencia. En algunos casos hay apropiación del término, en otros, aversión al mismo por parte de los especialistas en el tema quienes a su vez son llamados "violentólogos".

\section{Notas}

2. El sociólogo colombiano y Dr. en Investigación en Ciencias Sociales Jefferson Jaramillo retoma la noción "tramas narrativas" planteada por Paul Ricoeur $(2000,192)$. La "trama narrativa" "proporciona a la experiencia humana, ante todo inteligibilidad y coherencia narrativa, permitiendo un conjunto de combinaciones mediante las cuales los acontecimientos temporales se transforman en un relato estructurado. La trama es la mediadora entre la vivencia temporal y la acción narrativa, entre lo que acontece temporalmente y lo que adquiere sentido en una estructura de relatos" (Jaramillo, 2011a, 24)

3. Este discurso tuvo como antecedente el libro La Violencia en Colombia (1962) de Germán Guzmán, Orlando Fals Borda y Eduardo Umaña Luna, donde apareció bajo la metáfora "cadenas atávicas que signan el alma nacional" (Jaramillo, 2011a, 30), las cuales explicarían el desenlace violento entre las facciones partidistas que ya se venía consumando desde inicios de siglo.

4. El "Frente Nacional" derivó de una alianza política entre los partidos políticos tradicionales colombianos: Partido Liberal y Partido Conservador, para alternarse el poder durante el periodo de 1958 a 1974, con el objetivo de darle fin al ciclo de la violencia política.

5. El Estado moderno, según Max Weber, ejerce el monopolio de la fuerza física legítima en un territorio determinado. Desde la vertiente teórica marxista, por ejemplo, se postula que el Estado ejerce una violencia de clase. 
Marcos narrativos y emergentes contra-narrativos ...

6. Esta línea argumentativa está suscrita a los análisis sociológicos de Emile Durkheim quién se preocupa por los procesos desintegradores que genera la universalización de las relaciones mercantiles y el debilitamiento de los lazos religiosos que conduce a la anomia, propia de las sociedad industriales. 
(CVD) Presidencia de la República. (1995[1987]). Colombia: Violencia y

Democracia Comisión de estudios sobre la violencia. IEPRI. Colciencias.

Allier, E. (2010). Batallas por la memoria. Los usos políticos del pasado reciente en Uruguay. México, TRILCE-UNAM (IIS).

Franco, M. y Levín, F. (2007). Historia Reciente. Perspectivas y desafíos para un campo en construcción. Buenos Aires, Paidós

Sánchez, G y Peñaranda, R. (comp). (2007). Pasado y Presente de la Violencia en Colombia. La Carreta Histórica, Bogotá.

Guzmán G.; Fals Borda O y Umaña Luna (2010 [1962]). La violencia en Colombia. Tomo I y II. Bogotá, Aguilar. Alfaguara.

Palacios, M. y Safford, M. (2002). Colombia, país fragmentado, sociedad dividida. Bogotá, Editorial Norma.

Rubio, M. (1999). Crimen e impunidad. Precisiones sobre la violencia. Bogotá, Tercer mundo/Uniandes.

Deas, M. (2007). Algunos interrogantes sobre la relación guerras civiles y violencia. En Sánchez y Peñaranda (comp) Pasado y presente de la violencia en Colombia. Medellín, La Carreta; 81-85

Pécaut, D. (2003) Violencia y Política: cuatro elementos de reflexión teórica alrededor del conflicto colombiano. En Pécaut, Daniel. Violencia y Política en Colombia. Elementos de reflexión. Medellín: Hombre Nuevo Editores. 17-27.

Restrepo, D. (1990) Nuevos discursos sobre la violencia: Reciclaje del fetiche neoliberal. En Palacio (comp) La irrupción del paraestado. Ensayos sobre la crisis colombiana. Bogotá, ILSA-CEREC. 
Marcos narrativos y emergentes contra-narrativos ...

Foucault, M. (1994). Verdad y Poder. En Foucault, Obras esenciales. Barcelona, Paidós. 379-392 (1994a). La verdad y las formas jurídicas. En Foucault Obras esenciales. Barcelona, Paidós. Pp. 487-584.

Medellín Torres, P. (1990) La fascinación de la violencia. En Palacio (comp) La irrupción del pareaestado, ensayo sobre la crisis colombiana. Bogotá, ILSACEREC

Rabotnikof, N. (2007). Memoria y Política: el juego del tiempo en las transiciones México. Fundación Friedrich Ebert

Palacio, G. (1990). El discurso sobre la violencia: Hacia la reconstrucción de la neutralidad del estado neoliberal. En Palacio (comp) La irrupción del paraestado. Ensayos sobre la crisis colombiana. Bogotá, ILSA-CEREC

Gaitán Daza, F. (1989). Una indagación sobre las causas de la violencia en Colombia. En M. Deas y F. Gaitán Daza. Dos ensayos especulativos sobre la violencia en Colombia. Bogotá, Fonade/Departamento Nacional de Planeación.

Sánchez, G. (1993). Los intelectuales y la violencia. Revista Análisis Político. Núm. 19.

Gonzales, F y Pizarro, E (1989). Replanteamientos del origen de la violencia: Estructuras o Actores Políticos. Revista Universidad Nacional, Núm. 21.

Jaramillo Marín, J. (2011). Expertos y comisiones de estudio sobre la violencia en Colombia. Revista Estudios Políticos, Núm. 39, Instituto de Estudios Políticos, Universidad de Antioquia. 
Jaramillo Marín, J. (2011a). Las comisiones de estudio sobre la violencia en

Colombia: tramas narrativas y ofertas de sentido temporal para comprender la violencia. Tesis de Doctorado inédita. Doctorado en Ciencias Sociales. FlacsoMéxico.

Sánchez Díaz, C. (2009). Las palabras sobre la guerra. Historia crítica sobre el discurso académico sobre la violencia en Colombia. 1962-2007. Tesis inédita. Grado en Historiador. Universidad Pontificia Javeriana de Colombia. 